Meta

Journal des tradlucteurs

Translators' Journal

\title{
Translating Colour Collocations
}

\section{T. J. A. Bennett}

Volume 26, numéro 3, septembre 1981

URI : https://id.erudit.org/iderudit/002057ar

DOI : https://doi.org/10.7202/002057ar

Aller au sommaire du numéro

Éditeur(s)

Les Presses de l'Université de Montréal

ISSN

0026-0452 (imprimé)

1492-1421 (numérique)

Découvrir la revue

Citer cet article

Bennett, T. J. A. (1981). Translating Colour Collocations. Meta, 26(3), 272-281.

https://doi.org/10.7202/002057ar d'utilisation que vous pouvez consulter en ligne.

https://apropos.erudit.org/fr/usagers/politique-dutilisation/ 


\section{TRANSLATING COLOUR COLLOCATIONS}

While an Invited Professor at the University of Ottawa's School of Translators and Interpreters, the author developed an interest in colour collocations, largely as a result of tussling several times with the problems that they caused in particular texts that students were translating. The Director of the School kindly supported a request for computer space, and a corpus of some 2500 colour collocations (CCs) was assembled within some five months. This has now reached 4000 , and the collecting phase can now be considered well advanced; the corpus should be published during 1981. Besides looking at CCs in English, the project will eventually branch out into other languages, thus enabling comparative work to be carried out later. In the meantime, the initial impulse 
having come from the area of translation, it seems appropriate to make a first approach to the whole question of translation of CCs and, for the moment, especially the translations offered in two good, much-used dictionaries, namely Harraps Standard Dictionary ${ }^{1}(\mathrm{H})$ and the Collins Robert Dictionary ${ }^{2}(\mathrm{C})$.

CCs take a variety of forms, but their central defining characteristic is that they include a colour-word $(\mathrm{CW})$ as some part of speech or other, and combine it with other words. This can be extended to include potential collocations, in the sense that, if a CW has a given meaning that is not attached to any other word or group of words to form a known standard collocation, it can be regarded as basically belonging to the category of $\mathrm{CCs}$, e.g. the verb to blue (meaning "to dye blue") is not, usually, associated with a particular noun, but could occur with any of a whole series of nouns, so it can be counted as a potential $\mathrm{CC}$, even if a comparatively uninteresting one.

The most interesting $\mathrm{CCs}$ are doubtless those which are metaphorical, either through one element (often the colour-word), e.g. a blue film, or as a result of the meaning of the $\mathrm{CC}$ as a unit, e.g. once in a blue moon. It is probably an over-simplification to state that the expression $a$ blue film is metaphorical solely because of the word blue. We would generally agree with Weinreich (1969) that a process of mutual selection of meanings occurs in such expressions, i.e. that the meaning "pornographic" is selected from the meanings of blue by the word film (and also by the co-text and the context); in other words, film is responsible for the attribution to blue of this metaphorical meaning, and therefore it is not solely through the word blue that the collocation a blue film is metaphorical, but rather through the conjunction of blue and film. It nonetheless remains true that an expression such as once in a blue moon is basically unanalysable in the sense that it is difficult to say precisely where the meaning "hardly ever" resides in it, whereas one can clearly locate the meaning "pornographic" in a blue film. These CCs often belong to the category of idioms, which, it is well known, are frequently difficult to translate, as they bring in problems relating to the way in which languages analyse the world and consequently filter our experience of it, as well as problems such as stylistic level, colloquialness, etc. The problem of metaphor is even greater for the translator because this vast area, characterised in theory by reduction of the arbitraire $d u$ signe and therefore more straightforward, remains in fact an area of great arbitrariness, if only because, putting it rather simplistically, different languages identify different things in the world around us, and characterise these things differently; thus it is not surprising if the phrase the ship scythed through the ocean necessitates some circumlocution or paraphrasing if its full meaning is to be translated, since the French mind, conditioned as it partly is by the lexical, semantic and grammatical structure of French, does not see a ship as a scythe so easily as the English mind does.

Fortunately, not all CCs fall within the category of metaphor, but the majority probably do, according to the results of some preliminary research recently conducted by the author. As a basis for this first phase of a larger

1. Harraps Standard French and English Dictionary, 1966.

2. Collins Robert French-English, English-French Dictionary, 1978. 
project, a compilation was made of all the CCs listed under blue in $\mathrm{H}$ and $\mathrm{C}$, along with their French translations. These were subsequently transferred to colour-coded cards, according to whether the translation used a) the same $\mathrm{CW}$ (bleu) as the English, b) a different $\mathrm{CW}$, or c) no $\mathrm{CW}$. A separate card was also made for each meaning of an English CC. Thus, for example, two differentlycoloured cards were made for blue blood, as it is translated as sang bleu (using the "same" CW) and as sang noble (not using a CW). Similarly, three cards were prepared for blueprint, as, in one meaning, it is translated as photocopie bleue (same $\mathrm{CW}$ ) or reproduction héliographique (no $\mathrm{CW}$ ) and, in another meaning, as schéma directeur.

The resulting data-base consisted of 117 cards corresponding to eighty entry-CCs and containing 121 translations. The fact that there were not more translations is doubtless a reflection of the structure of dictionaries, which often offer only one translation of phrases and expressions, even if they offer many translations of individual words. This material was examined, and, firstly, each $\mathrm{CC}$, then each translation was classified as literal, elliptical, or metaphorical (taking a possibly rather wide interpretation of metaphorical). On occasions, it was difficult to decide whether a $\mathrm{CC}$ in fact belonged to the second or third category, so these two were condensed into a single category for statistical purposes.

\section{SAME COLOUR-WORD}

Taking, firstly, the cases where the same CW occurs in French and English, one obtains the following breakdown of frequencies:

TABLE I

Colour collocations using the same colour-word in English and French

\begin{tabular}{|c|c|c|c|}
\cline { 3 - 4 } \multicolumn{2}{c|}{} & \multicolumn{2}{c|}{ English } \\
\cline { 3 - 4 } \multirow{2}{*}{ French } & Literal & Metaphorical \\
\hline & Literal & 18 & 5 \\
& Metaphorical & 0 & 11 \\
\hline
\end{tabular}

That the largest single group is those where the English and the French CCs are literal is not surprising, since the "literal" meaning of a colour is arguably its basic meaning, about which one can expect a substantial amount of agreement between English and French. Thus, for example, blue spectacles is translated as lunettes bleutées, or to beat someone black and blue as battre quelqu'un tout bleu. This second example is, of course, debatable, but it arguably satisfies the criterion that the same $\mathrm{CW}$ is used in both languages; the addition of black only means that the English $\mathrm{CC}$ could be regarded as belonging to a subgroup of the category under consideration. A third example would be the now-practicallyunknown washing blue, which is translated as bleu d'empois. Given the strong appeal of colour to the human visual sense, and its importance as an identifying feature, one would expect the instances where both $\mathrm{CCs}$ are literal to pre- 
dominate in the cases where both languages use the same $\mathrm{CW}$. The second largest group is, perhaps more surprisingly, that where the $\mathrm{CC}$ in both languages is metaphorical. This is surprising because of a) the quite high degree of arbitrariness in metaphor, b) the arbitrariness of colour perception in fairly concrete cases (one imagines the arbitrariness of the choice of $\mathrm{CW}$ can only increase - if one compares two languages - as the usage becomes more metaphorical). An interesting example where usage is uncertain is that of Blue Book (Brit. Parl.), which is translated in $\mathrm{C}$ as livre bleu, but in $\mathrm{H}$ as livre jaune. Native speakers who were consulted about the question generally thought that livre jaune was old-fashioned (an opinion confirmed by the Dictionnaire Larousse) and that livre bleu or livre blanc (the latter possibly a calque on white paper) were better renderings. In fact, such French Parliamentary information papers seem to have a very flexible nomenclature, and livre vert was also thought to be appropriate, especially if the topic was connected with ecology. The translation offered in $\mathrm{H}$ is, in fact, not just obsolescent (presumably it will be replaced when the revised version of the English-French volume appears), but, in its historical context, of doubtful accuracy. If one looks in the Petit Larousse of 1952, the definition given of livre jaune is "un recueil de documents diplomatiques distribués au Parlement français", which is certainly a long way from that of a Blue Book ("an official report of Parliament and the Privy Council", Shorter Oxford). The translation of Blue Book as livre jaune is, in fact, so off target as to remind one of the question raised by $\mathrm{Nida}$ (1959) as to whether one can claim, for example, to translate vine correctly if one uses the name of a plant which (unlike the vine) is within the experience of the users of the target language, but which is not cultivated and does not bear fruit: even taking a fairly liberal view, it seems doubtful whether such a "translation" is worthy of the name, though it may, in certain circumstances, be sufficient.

Another example from the category under consideration is bolt from the blue, which $\mathrm{C}$ translates as un coup de tonnerre dans un ciel bleu. One is struck by the close similarity of the two CCs, not just the use of the same $\mathrm{CW}$. Given the proximity of France to England, one could expect a number of similar images to occur in both languages, even if English and French were unrelated. C's translation seems better than $\mathrm{H}$ 's rather uninspired version (événement imprévu), as it is almost exactly the same metaphor as in English, and is idiomatic and current in present-day French. However, a consensus among the French speakers consulted could not be found, some maintaining that the phrase dans un ciel bleu was not idiomatic, and that un coup de tonnerre was sufficient.

The only other significant category is again one which one would expect to be reasonably frequent, namely those cases where a metaphorical English $\mathrm{CC}$ is translated by a non-metaphorical French one, e.g. blue-john: fuorine bleue. Naturally, some of the metaphors are glossed or defined in English, rather than being translated by a corresponding metaphor, e.g. to blue-pencil : marquer au crayon bleu. Given the nature of metaphor and the arbitraire du signe, many metaphors in one language are bound to have no corresponding metaphor in another language. 


\section{DIFFERENT COLOUR-WORD}

If one examines the CCs whose translations contain a different $\mathrm{CW}$ from that used in the English version, the statistical breakdown looks somewhat different, even allowing for the smaller total number of collocations involved.

TABLE II

Colour collocations using different colour-words in English and French

\begin{tabular}{|l|c|c|c|}
\cline { 3 - 4 } \multicolumn{2}{c|}{} & \multicolumn{2}{c|}{ English } \\
\cline { 3 - 4 } \multirow{2}{*}{ French } & Literal & Metaphorical \\
\cline { 3 - 4 } & Literal & 5 & 4 \\
& Metaphorical & 0 & 7 \\
\hline
\end{tabular}

Conceivably, the numbers involved are too small to have great significance attached to them, but there is a noticeable difference from Table $I$, in the sense that, this time, the largest group is that where a metaphorical English CC corresponds to a metaphorical French one. In any event, some of the actual cases that provide the statistics for Table II are worthy of comment. Duczmal (1979) instances a rare (and remarkable) case of reverse equivalents in the English and Polish names for the same animal, namely the black swan, which is known in Polish as the "white swan" (biay kruk)! There is nothing so startling among the CCs culled from $\mathrm{H}$ and $\mathrm{C}$, but they do show how perceptions of the same reality can vary according to the language a person speaks. Leaving aside the doubtful example already discussed, namely $(\mathrm{H})$ Blue book: livre jaune, the pair with the greatest distance between them are $(\mathrm{H})$ blue dahlia: merle blanc, both of which are highly metaphorical, but, interestingly, exhibit a high degree of arbitrariness, except inasmuch as both use a noun plus a CW to express the same idea, whereas any other kind of modifier would have suited the purpose equally well. A further parallelism is that both English and French search for the most unlikely (therefore most extreme) colour in the context of the usual colour of the referent of the noun. In the case of the merle, the choice is simple, since noir has a direct opposite, namely white. In the case of dahlia, a colour has been chosen that does not exist in dahlias and is therefore also a kind of opposite of those colours that characterise the flower referred to.

The next most extreme divergence in terms of the $\mathrm{CW}$ used is that found in $(\mathrm{H})$ the blues: humeur noire or papillons noirs, together with $(\mathrm{H})$ have a fit of the blues: avoir des idées noires or avoir un accès d'humeur noire or broyer $d u$ noir. $C$ offers humeur noire and broyer $d u$ noir, along with le cafard (also given by $\mathrm{H}$ ), which does not belong in this section. The metaphor contained in the French $\mathrm{CW}$ is fairly straightforward, not to say conventional, though the proffered papillons noirs seems a little weak, as there are black butterflies, though they are certainly less attractive than their more colourful counterparts. The CW used in the English version seems highly arbitrary, though, if one regards it as deriving, ultimately, from the blue devils, it appears a little less so. 
Apart from the translations discussed above, the remaining instances in this category are only just within it, in the sense that each translation contains a different $\mathrm{CW}$ from the one used in English, but the $\mathrm{CW}$ chosen is either a near synonym of that used in English or is the name of a fairly similar colour. An example of the first type of expression is to blue (linen), which $\mathrm{H}$ translates as azurer (du linge). The other type is exemplified by blue with cold, which $\mathrm{H}$ translates as violet or violacé de froid (as well as bleu de froid, also given by C). Arguably, in the case of azurer (du linge), the difference in $\mathrm{CW}$ is purely technical, but, since there are also bleuir and bleuter (used in other contexts), it seems legitimate to maintain that there is a difference. With bleu: violet/viola$c e ́$, on the other hand, we have a clear case where the colours named really are different and where either violet/violacé is an arbitrary choice of term to designate a given colour, or the choice of either of these CWs as opposed to bleu is an expression of a difference in perception of the objective reality referred to. A third possibility is that the colour is perceived as being very much at the borderline between bleu and violet, so that either can be used (without much significance being attached to the use of one rather than the other), and the choice is a fairly arbitrary one between two possibilities.

\section{NO COLOUR-WORD}

The last category examined in this study was that of English CCs that are translated not by French CCs but by collocations or expressions that contain no $\mathrm{CW}$. The statistical breakdown relating to this category is as follows :

TABLE III

Colour collocations in English translated by expressions not using a colour-word

\begin{tabular}{|c|c|c|c|}
\cline { 3 - 4 } \multicolumn{2}{c|}{} & \multicolumn{2}{|c|}{ English } \\
\cline { 3 - 4 } \multicolumn{2}{|c|}{ French } & Literal & Metaphorical \\
& Literal & 12 & 48 \\
& Metaphorical & 1 & 10 \\
\hline
\end{tabular}

The most striking thing about the above table is the enormous figure of 48 for those metaphorical English CCs that are translated by a literal expression in French. This means that, of twelve possible categories examined, this one alone contains $39.6 \%$ of all the examples found in the two sources that were examined. Some examples are: blue-blooded: de sang noble; have a blue fit: piquer une crise; be in a blue funk: avoir la frousse; a blue-jacket: un marin de l'État; beat someone black and blue: rouer quelqu'un de coups; true-blue : fidèle; the Blues : la Cavalerie de la Maison du Roi. While striking, the figure should not be totally surprising, since, apart from the factors already alluded to (the arbitrary nature of metaphor, etc.) it is obviously easier, when compiling a bilingual dictionary, to resort to a gloss rather than search long and hard for a good translation (one can fully appreciate that it might on occasions be too timeconsuming, or even simply impossible, to locate the best translation, in an absolute sense). That the search is given up as being not worth the candle 
doubtless only applies in a (small?) minority of cases, and, clearly, a gloss can be the only possible way to translate something, when the idea or object referred to has no parallel in the target language. An example of this is the American meaning of Blue Book, which $\mathrm{H}$ translates as registre des employés de l'État. One can imagine the problems that might be caused by such an unwieldy rendering, but it is difficult to see what else can be done to translate Blue Book in this meaning. A translator faced with a situation where the blueness of the book and its exact nature and function were both important would probably have to abandon $\mathrm{H}$ 's version and resort to the expedient of a literal translation, with an appropriate footnote enumerating the relevant semantic features that the (misleading or quasi-incomprehensible) literal translation should be understood as possessing; only thus could the translator ensure that the reader understood the full meaning of the text. Other examples include: blue-coat : élève des écoles de Christ's Hospital; Blue laws : lois inspirées par le puritanisme; bluenose : habitant(e) de la Nouvelle-Écosse.

The next biggest group is those literal English CCs that are translated with literal expressions in French (but without a CW). While the literal-toliteral group predominates when both languages use the same $\mathrm{CW}$, it trails far behind the metaphorical-to-literal group, here. This is logical, since, when the same $\mathrm{CW}$ is used, the two languages seem most likely to use it when being literal. Conversely, when English uses a metaphorical CC, but French uses no $\mathrm{CW}$, the French translation of the English CC seems most likely to be a literal expression of some sort, though not a literal translation of the English CC. Typical of this group are such pairs as blue ointment : onguent mercuriel double; blueprint : reproduction héliographique; blue-grass : pâturin des prés. The translations offered in this category are often fairly akin to definitions, and are reminiscent of the glosses that are offered as translations of several of the CCs in the metaphorical-to-literal group presented in the previous paragraph. This is presumably attributable to the fact that the $\mathrm{CW}$ in the English collocations is prominent and distorts the perception of the referent, the colour having, so to speak, more than its objectively correct share of importance in the picture of the referent painted by the words, e.g. the colour of blue-grass is one that many people would probably not call blue, but it is blue in comparison with ordinary grass, so this fact becomes the main identifying feature of the grass, because colours are a thing that strike our visual sense with considerable force and immediacy. This reflects a tendency that can be seen, in many CCs, to pick on an often quite small, coloured part of something and either to refer to the thing through that coloured part or through the colour of that part (especially noticeable with reference to uniforms), e.g. the Red Berets, the Black Horse (the 7th Dragoon Guards, whose facings are black), a whitewing (chaffinch) or a scarlet runner (a bean with red flowers).

The most surprising thing to emerge in this third category is that the metaphorical-to-metaphorical group is only slightly smaller (ten meanings) than the literal-to-literal group. This is surprising in view of the fact that there is no $\mathrm{CW}$ in the French translations, a fact which would lead one to imagine that nearly all translations would be of the literal type, a good proportion of them being glosses. An example where, despite the absence of a $\mathrm{CW}$, the metaphor is 
basically the same is (C) come out of the blue : tomber du ciel. A closelyrelated metaphor has a totally different, but still metaphorical, translation: (H) out of the blue : à propos de bottes. Other examples include $(\mathrm{H})$ turn the air blue: jurer comme un charretier; (C) like a blue streak: au triple galop; (C) blueprint : schéma directeur; $(\mathrm{H})$ once in a blue moon: tous les trente-six $d u$ mois. The majority of this surprising group are of a type that one might loosely characterise as fairly powerful or eloquent images expressing concepts that are likely to be useful quite often, hence the existence of parallel (though not usually similar) metaphors in the other language.

From the figures in Table IV, one is tempted to try to draw conclusions about the comparative tendencies of English and French to use metaphor, with or without CWs. This would be a hazardous undertaking, since the study was carried out solely in the direction English-French and through two dictionaries (not by a more direct sampling method), which means that a) most of the major collocations of blue were counted (whereas it would be much more difficult to find a comparable collection of collocations (metaphorical or otherwise) of bleu), and b) conceivably, French metaphors and CCs that would have served to translate English CCs were unknown to the compilers of the dictionaries, and so failed to appear. In any case, blue may not be a colour that appeals much to the French, or it may be one that has certain connotations or overtones that tend to inhibit its use in French metaphors and CCs.

TABLE IV

Composite Table of Frequencies.

\begin{tabular}{|c|c|c|c|c|c|c|c|c|}
\hline & & \multicolumn{6}{|c|}{ English } & \multirow[b]{2}{*}{ Totals } \\
\hline & & \multicolumn{2}{|c|}{ Same CW } & \multicolumn{2}{|c|}{ Different CW } & \multicolumn{2}{|c|}{ No $\mathrm{CW}$ in French } & \\
\hline & & Literal & Metaphorical & Literal & Metaphorical & Literal & Metaphorical & \\
\hline \multirow{3}{*}{ French } & Literal & 18 & 5 & 5 & 4 & 12 & 48 & 92 \\
\hline & Metaphorical & 0 & 11 & 0 & 7 & 1 & 10 & 29 \\
\hline & Totals & 18 & 16 & 5 & 11 & 13 & 58 & 121 \\
\hline
\end{tabular}

The imbalance between the totals of English, as opposed to French, metaphorical expressions $(85: 29)$ and those of English, as opposed to French literal expressions $(36: 92)$ is such as to suggest that there is a distortion of some sort present, which means that such comparative figures would have a very shaky basis. In fact, a quick check was made of the results obtained if the enquiry was reversed (i.e. one started from bleu, not blue), and 34 meanings of French $\mathrm{CCs}$ incorporating bleu were found that had not been discovered when the direction of working was English-French. Of these, 31 were metaphorical, whereas only 7 were so in English; in English, 28 incorporated no $\mathrm{CW}$. Thus, it is clear that bilingual dictionaries distort the picture of comparative use of metaphors and Cs, unless one at least compares the patterns prevailing in both directions (in this particular case, English-French and FrenchEnglish). Whether the comparison is valid even then is debatable, but, at least, 
one can hope that certain distortions will tend to cancel each other out (though one must beware, in case others are added together!). It was, in any case, not the aim of this study to arrive at statements about the comparative use of metaphor in CCs in English and French, so we have not conducted the full reverse enquiry. The aim was, rather, to examine what sorts of English CCs were translated into French in the sources mentioned, and how the suggested translations compared to the English CCs.

It emerges from the material examined and the related data that $\mathrm{CCs}$ are a problem for compilers of bilingual dictionaries, not least because selection is necessary. The author's collection of CCs incorporating blue has practically reached 300 , and the listed meanings have passed the 370 mark (compared to 80 entries and 100 meanings noted in the material examined for this study). It seems likely that the problem of selection in part explains why practically two fifths of the translations collected are of metaphorical English CCs (presumably the most difficult to understand and/or translate) which come out in French as literal expressions without CWs, often basically as glosses in French of the English CCs. Since the referents of the CCs are often peculiar to the English context, this is probably the best procedure (since a literal translation would usually be incomprehensible), and the bilingual dictionary thus also becomes in part a bilingual encyclopedia.

It also emerges that metaphor is fairly arbitrary, despite the theoretical limitations that it places on the arbitraire du signe. Only 11 metaphorical meanings out of 121 are translated into metaphorical French CCs with the same $\mathrm{CW}$; another seven are translated into a metaphor with a different $\mathrm{CW}$. It would be interesting to conduct a survey of a wide range of metaphors to see how closely the figures obtained for translation by a similar metaphor correlated with those for CCs.

Lastly, the fact that only approximately one quarter of the number of $\mathrm{CCs}$ collected by the author is translated by $\mathrm{C}$ and $\mathrm{H}$ together suggests that there is a need for dictionaries of CCs to be compiled and published in each of the world's major languages (as the author is doing for English), so that this difficult area of language is at last well mapped for translators and others who need to find their way around it.

T.J.A. BENNETT

\section{BIBLIOGRAPHY}

DUCZMAL, Stanislav (1979): "A contrastive semantic analysis of colour adjectives in Polish and English', in Papers and Studies in Contrastive Linguistics, vol. 9, Poznán, p. 181-191. NIDA, Eugène A. (1959): "Linguistics and ethnology in translation Problems", in On Translation, ed. Brower, Cambridge, Mass., Harvard University Press.

WEINREICH, Ulrich (1969): "Problems in the Analysis of idioms", in The Substance and Structure of Language. 